\title{
Haematopoietic Stem Cell Transplantation in Tanzania
}

Janeth Mtenga ${ }^{1}$, Kate Orf 2, Jiexin Zheng 2, Clara Chamba ${ }^{1}$, Harrison Chuwa ${ }^{3}$, Frederick Luoga 1,4, Stella W Malangahe 5, Per Ole Iversen 1,67, Julie Makani 1,4

${ }^{1}$ Department of Haematology, Muhimbili University of Health and Allied Sciences, Dar es Salaam, Tanzania, ${ }^{2}$ Department of Haematology, University College London Hospital, London, UK, ${ }^{3}$ Department of Haematology, Aga Khan Hospital, Dar es Salaam, Tanzania, 4 Sickle Cell Programme, Department of Haematology, Muhimbili University of Health and Allied Sciences, Dar es Salaam, Tanzania, ${ }^{5}$ Department of Haematology, Benjamin Mkapa Hospital, Dodoma, Tanzania, 6 Department of Haematology, University of Oslo, Norway, 7 Department of Nutrition, University of Oslo, Norway

\section{Keywords: Tanzania, stem cell transplant, sickle cell disease}

Haematopoietic stem cell transplantation (HSCT) is a much-needed service in Tanzania that will provide curative therapy for sickle cell disease (SCD), aplastic anaemia and haematological malignancies. The experience of countries with limited resources has demonstrated that it is possible to set up such a service within similar economic and healthcare settings. This article summarises the current progress that has been made towards setting up this service and highlights the areas that require on-going work and investment to make HSCT a service in Tanzania a reality.

Unmet needs of stem cell transplantation in low to middle income countries Haematopoietic stem cell transplantation (HSCT) is the standard of care for patients with inherited and acquired haematology disorders. Both autologous and allogeneic stem cell transplants take place in HSCT centres worldwide, and are concentrated in high-income countries (HIC) due to the significant healthcare resources required. Allogeneic and autologous HSCT activity is increasing worldwide with a mean seven percent year-on-year increase in the last twenty five years, with increasing demand for HSCT centres in low and middle income countries (LMIC) (Niederwieser D 2019) (Baldomero, et al 2019), Das, et al (2018), (Ruiz-Delgado and Ruiz-Arguelles 2012). The establishment of a HSCT centre requires optimal patient care before, during and after the transplant period, donor care pretransplant as well as appropriate laboratory facilities. This may be difficult to achieve in LMIC due to inadequate infrastructure, funding and diagnostic services (Bazuaye, et al 2014, Kulkarni and George 2019).

In this article we describe the current status of HSCT in Tanzania, which does not have a HSCT centre. Currently HSCT centres are located only in Nigeria and South Africa (Harif, et al 2019), with countries such as Ghana exploring the possibility of setting up centres. If patients require a HSCT in Tanzania, they are referred to centres in countries such as India and require either personal funding or insurance coverage.

In Tanzania, SCD has been prioritised as one of the medical conditions that can be treated by HSCT. SCD is a global health issue, but the impact is most significant in Africa, where over $80 \%$ of the yearly global 305,000 affected births occur (Piel, et al 2013). Allogeneic HSCT (allo-HSCT) is a curative option in patients with SCD, with general consensus recommending early HSCT in young patients with clinically severe SCD with an HLA-matched donor (Angelucci, et al 2014, Bernaudin, et al 2019, Bhatia and Sheth 2015, Eapen, et al 2019). Aplastic anaemia is another condition that can be treated with HSCT. An observational study 
conducted at a teaching hospital in Dar es Salaam reported a high incidence of aplastic anaemia, with a mortality rate of $48 \%$ (Ally, et al 2019). 85\% of patients diagnosed had severe or very severe AA, with $80 \%$ being diagnosed under the age of 40 . The third haematological condition that is an indication for HSCT is leukaemia, both acute and chronic forms. Accurate estimates on incidence of acute leukaemia is difficult to obtain due many issues, including variability in hospital diagnostics and late presentation. However, 2018 estimates from the Global Cancer Observatory estimates a yearly incidence of 1898 in Tanzania for haematological malignancies, including non-Hodgkin lymphoma, leukaemia, Hodgkin's lymphoma and multiple myeloma (Bray, et al 2018). This accounts for just under five percent of all new cancer diagnoses.

HSCT is a high-risk procedure with a significant associated mortality even in established HSCT centres. Causes of transplant related mortality include infection, graft versus host disease (GVHD) and end organ toxicity. (Gluckman, et al 2017). The associated risks mean effective pre-, peri- and post- transplant care is needed to ameliorate these risks to the patient; therefore in the establishment of a new HSCT centre recognised standards need to be met before the first patient can be transplanted. The data described here comes from the archives of the Sickle Cell Programme at Muhimbili University of Health and Allied Sciences (MUHAS), three specialist hospitals and a systematic PubMed search. Two clinical fellows from the UK collated this information during their fellowship at MUHAS in September 2019 and used information from clinical audit conducted as part of haematology fellowship by a Clinical fellow from Tanzania.

Stem cell transplant programmes in Tanzania

Over the last few years, there has been increasing awareness of the worldwide inequality of availability of HSCT. This has led to initiatives by governments, charities and regulatory bodies such as the World Health Organisation (WHO) and Joint Accreditation Committee of the International Society for Cellular Therapy (JACIE) to try to reduce this (Pasquini, et al 2019, Snowden, et al 2017). The Worldwide Network for Blood and Marrow Transplantation (WBMT) recently published recommendations on the establishment of a new transplantation program (Aljurf, et al 2019, Pasquini, et al 2019). As of 2019 one billion Africans have HSCT available in only two countries: South Africa and Nigeria. South Africa has an established transplant programme and performs around 250 autologous transplants and 175 allogeneic transplants per year (Harif, et al 2019). Nigeria established an allogeneic HSCT programme in 2011 for SCD and has performed six transplants (Harif, et al 2019).

The Sickle Cell Programme within Muhimbili University of Health and Allied Sciences (MUHAS) in Dar-es-Salaam, Tanzania has been developing an agenda to establish HSCT in Tanzania since 2016, following a directive from the Ministry of Health. MUHAS is a university with a strong history of national and international collaborative research projects within haematology and other specialties, with particular experience and expertise in SCD.

Issues faced in establishing an HSCT program in Tanzania

Some key initial requirements to establishing an HSCT programme are hospital-support and appropriate leadership for an HSCT programme, developing links with well-established HSCT institutions and securing funding. Once these are fulfilled, the next requirement centres around personnel training, hospital infrastructure, diagnostic and laboratory services, pharmacy and vaccination, stem cell processing, and securing a source of blood products and 
stem cells (Aljurf, et al 2019, Pasquini, et al 2019). Figure 1 illustrates aspects required to establish a HSCT programme.

\section{Training and partnership}

The first aspect is partnership: almost all case studies examining the establishment of a new HSCT unit in a LMIC mention the importance of pairing a nascent programme with a wellestablished centre elsewhere (Das, et al 2018, Faulkner 2013, Yeh, et al 2018). This can be facilitated by having a medical director who is a haematologist, oncologist or immunologist with experience in HSCT. Bangladesh established their autologous HSCT centre in Dhaka with the support of Massachusetts General Hospital (Yeh, et al 2018). In India, the establishment of a HSCT unit in Rajasthan was facilitated by the Cure2Children foundation (C2C) which paired the developing Indian HSCT unit with an established Italian hospital (Bhatia and Sheth 2015). Expertise in medical, nursing and laboratory personnel are essential to the successful establishment of a HSCT service. Achieving this expertise is can be facilitated by twinning with a more experienced centre. This allows both effective training of staff but also on-going support and advice in running the service, along with management of quality standards.

Tanzania has recognised this and has been actively seeking collaborative partners. The C2C foundation is an Italian non-governmental organisation that has successfully established HSCT centres within hospitals with minimal oncology and chemotherapy background through structured collaboration and focused training (Faulkner 2013). MUHAS has ongoing educational collaboration with $\mathrm{C} 2 \mathrm{C}$, running educational courses for clinicians in Africa. In addition to this, a link has been established with the Université Paris Diderot in France, where Tanzanian clinicians have been on short-term training fellowship at the Assistance Publique Hopitaux de Paris. MUHAS has experience in setting up their own postgraduate haematology training programme (Makani, et al 2017), and plan to expand this by offering transplant fellowships. From a nursing perspective, a curriculum is under development and discussions are on-going with partners such as University of Oxford regarding establishing a training programme. A strategy has been developed for the laboratory outlining development requirements and staff training needs, including HLA typing and stem cell collection, processing and storage.

Benjamin William Mpaka Hospital (BMH) in Dodoma, Tanzania has twinned with a transplant centre in Monza, Italy. Currently there are clinicians, nursing staff and a medical director who have undergone training in HSCT working at BMH. The Aga Khan Hospital $(\mathrm{AKH})$ which is part of regional and global health services has collaborated with the Sickle Cell programme at MUHAS to establish HSCT services. AKH will draw on its expertise and experience from the countries with East Africa (Kenya) as well as countries in Europe (France) and North America (Canada).

\section{Financing HSCT services}

It is not surprising that globally HSCT centres are associated with higher GDP per capita, government healthcare expenditure and human development index (Gratwohl, et al 2010). There are limited data on the cost of setting up a HSCT centre. However, the C2C have estimated costs of between 150,000 and 200,000 USD to set up a transplant centre (Faulkner, et al 2013). In LMIC, costs vary depending on country and allogeneic or autologous transplantation but are between 9,000 and 18,000 USD per transplant (Yeh, et al 2018). Both governments of Nigeria and Bangladesh funded the establishment of the transplant centre and initial transplants. Other countries have relied on a combination of 
governmental and charitable funding (Faulkner, et al 2013). Multiple strategies have been utilised to lower the cost of HSCT in LMICs (Gomez-Almaguer 2002). These include strategies that are now also used in HICs, such as increased use of ambulatory care and peripheral blood stem cells. In Tanzania, MUHAS aims for the HSCT units to be selfsustaining financially from research collaborations, private health care, outreach programmes as well as education and training. There have been proposals to secure funding for the project through international development programmes and financing from the private sector e.g. pharmaceutical and laboratory companies. The government of Tanzania has made considerable investment in tertiary health services with the opening of a state-ofthe-art hospital, Muhimbili National Hospital (MNH) in Mloganzila, which has the capacity to host a HSCT centre.

Identifying donors: stem cells and blood products

One of the key components in HSCT is strengthening the availability of blood products and developing capacity for blood irradiation, stem cell collection, processing and storage. These requirements pose significant problems due to their availability and cost. With regard to blood products, the Tanzania National Blood Transfusion Service (NBTS) has greatly increased its capacity for providing blood products. Furthermore, MNH, BMH and AKH have hospital transfusion services: collecting, processing, screening and allocating blood products. However, the demand for blood exceeds its supply in both hospitals and the NBTS, with the latter estimating that it can meet approximately $30 \%$ of requests for blood. This is despite having increased annual donations over 14-fold between 2005 to 2014 to 171,300 donors (Drammeh, et al 2018). NBTS and BMH are expanding their capacity for blood component collection and preparation and have procured or an in the process of procuring an apheresis facility for stem cell collection and platelet harvesting.

At MUHAS, a programme is under development to establish a stem cell registry for SCD patients, related and unrelated donors, initially starting with one thousand patients and siblings and one hundred unrelated donors. The aim is to lay the foundations for HSCT, and this will also demonstrate to prospective partners the feasibility of HSCT in Tanzania. Currently the Sickle Cell Programme has had discussions with the Sunflower Fund and Be The Match, both non-profit stem cell registries, regarding the establishment of a stem cell registry in Tanzania.

\section{Medicines and Vaccinations: Role of the Pharmacy}

The use of conditioning chemotherapy, immunosuppressant agents, and supportive medications during the transplant as well as antimicrobial, antifungal and antiviral agents are a necessary part of HSCT. The establishment of a pharmacy capable of supplying as well as monitoring these drugs is part of the minimum requirement for establishing the transplant centre (Pasquini, et al 2019). Supply from the private sector and donations remain the main sources of chemotherapy (Leak, et al 2020).

\section{Diagnostic services}

Laboratory services required for HSCT include flow cytometry to establish blood phenotypes including CD34 counts for stem cell collection, measuring blood levels of immunomodulatory drugs (e.g. ciclosporin and tacrolimus), donor/recipient chimerism analysis and PCR analysis for viral pathogens. These are all necessary parts of the HSCT service, but do not necessarily need to be done within the country. For example, the Bangladesh centre outsourced advanced diagnostics to more established laboratories in India (Yeh, et al 2018). In Tanzania, the Sickle Cell Programme has established a curriculum 
for laboratory personnel as well as identifying which tests would take place in Tanzania and which could be outsourced. Alternatives to outsourcing include repurposing existing laboratory machines to improve diagnostics. This has the advantage of reducing costs and test turnaround times, and has been used to improve diagnostic services at the Kilimanjaro Christian Medical Centre in Moshi (Leak, et al 2020). In addition to laboratory-based diagnostics, availability of radiology services in the transplantation centre ( $\mathrm{x}$-ray and CT) is also an essential component of the program (Pasquini, et al 2019).

\section{Infrastructure}

HSCTs in HIC have been conducted in isolation rooms with HEPA-filtered air, but are not a requirement for HSCT. Furthermore, these are not currently available in most hospitals in LMICs and require a significant financial investment to build and maintain. Dedicated units with either HEPA filtration (Nigeria) or regular monitoring of air and water colonies (Bangladesh) were constructed in new HSCT centres (Bazuaye et al, 2014, Yeh et al, 2018)

\section{Quality assurance and standards}

Historically, the method of assessment of the standards of a new HSCT centre is through the JACIE and EBMT. The European Bone Marrow Working Group established JACIE in 1998. The aim was two-fold: to provide a set of agreed quality standards for HSCT and provide formal accreditation for HSCT centres with regular inspections. The JACIE standards have also been developed in collaboration with Foundation for the Accreditation of Cellular Therapy (FACT) in the United States and the same standards apply across all centres worldwide. JACIE has performed accreditation inspections of around $40 \%$ of transplant centres in Europe and other HSCT centres worldwide. Currently almost all JACIE accredited centres are situated in HIC. The costs and infrastructure involved in establishing HSCT are significant and adding an extra set of quality standards and inspections to the process increases complexity and expenditure. JACIE has recognised the need for more HSCT centres in LMIC and have therefore developed a stepwise approach to HSCT accreditation for centres in this position. They have prioritised certain standards to try to reduce the high cost involved, aiming for HSCT centres in LMICs to build on these standards once established, and also makes entry-level accreditation for LMIC more attainable (Snowden, et al 2017). Another organisation ensuring HSCT quality standards, WBMT, also have a similar step-wise approach for accreditation that facilitates development in LMICs (Hashmi, et al 2017).

\section{Moving forward}

The programme to achieve stem cell transplantation in Tanzania has made substantial progress since inception in 2016. Given that transplantation is a goal of several centres across the country, consolidation of efforts to form a national collaborative effort is key to accelerate progress. This has been recognised by the Sickle Cell Programme at MUHAS with inter-hospital discussions about locations most suited to a HSCT centre. Moving forward, governmental policy to direct the formation of a national taskforce that includes representatives from governmental healthcare policy makers, hospitals, universities and Tanzanian NBTS. This allows a united approach and will reduce duplication of efforts. Division of responsibilities within the taskforce creates accountability and allow representatives to focus on areas in which they have a specialty interest. There should be identification of one or two centree to focus on with the aim of expanding access throughout the country and disseminating training in other hospitals once the centre has been successfully established. Co-operation between different centres may enable a more unified approach to securing national and international funding. Recent experience in establishing 
HSCT centres in Saudi Arabia demonstrates benefit in collaboration, with reduction in overall cost and project duration (Al-Hashmi, et al 2020).

Many of the factors described currently faced by Tanzania which limit establishment of HSCT services are similar to those faced in other LMIC. Therefore, the strategy for developing a HSCT centre in Tanzania could be used as a model for other countries. The WBMT has outlined practical requirements for establishing a HSCT centre: attempts at practically using their guidance is essential to highlight potential roadblocks for other countries adopting a similar blueprint.

The international HSCT community has a responsibility to promote and develop centres within LMIC. This has been started with guidance from WBMT and JACIE towards developing HSCT centres, however more practical assistance with funding and twinning would help drive progress forward through into the next stage.

\section{$\underline{\text { References }}$}

Al-Hashmi, H., Alsagheir, A., Estanislao, A., Bacal, J., Alsuhebah, A., Alblowe, B., Raslan, H., Alsaber, A., Albahrani, A., Almulhem, N., Alamri, A., Alsaleh, K., Albeihany, A., Alabdulwahab, A., Bakkar, M. \& Kaloyannidis, P. (2020) Establishing hematopoietic stem cell transplant programs; overcoming cost through collaboration. Bone Marrow Transplant, 55, 695-697.

Aljurf, M., Weisdorf, D., Hashmi, S.K., Nassar, A., Gluckman, E., Mohty, M., Rizzo, D., Pasquini, M., Hamadani, M., Saber, W., Hari, P., Kharfan-Dabaja, M., Majhail, N., Gerges, U., Ali Hamidieh, A., Hussain, F., Elhaddad, A., Mahmoud, H.K., Tbakhi, A., Othman, T.B., Hamladji, R.M., Bekadja, M.A., Ahmed, P., Bazarbachi, A., Adil, S., Alkindi, S., Ladeb, S., Dennison, D., Patel, M., Lu, P., Quessar, A.E., Okamoto, S., Atsuta, Y., Alhejazi, A., Ayas, M., Ahmed, S.O., Novitsky, N., Srivastava, A., Seber, A., Elsolh, H., Ghavamzadeh, A., Confer, D., Kodera, Y., Greinix, H., Szer, J., Horowitz, M. \& Niederwieser, D. (2019) Worldwide Network for Blood and Marrow Transplantation (WBMT) recommendations for establishing a hematopoietic stem cell transplantation program in countries with limited resources (Part II): Clinical, technical and socio-economic considerations. Hematol Oncol Stem Cell Ther.

Ally, M., Magesa, P. \& Luzzatto, L. (2019) High frequency of acquired aplastic anemia in Tanzania. Am J Hematol, 94, E86-E88.

Angelucci, E., Matthes-Martin, S., Baronciani, D., Bernaudin, F., Bonanomi, S., Cappellini, M.D., Dalle, J.H., Di Bartolomeo, P., de Heredia, C.D., Dickerhoff, R., Giardini, C., Gluckman, E., Hussein, A.A., Kamani, N., Minkov, M., Locatelli, F., Rocha, V., Sedlacek, P., Smiers, F., Thuret, I., Yaniv, I., Cavazzana, M., Peters, C., Error, E.I. \& Parties, E.P.W. (2014) Hematopoietic stem cell transplantation in thalassemia major and sickle cell disease: indications and management recommendations from an international expert panel. Haematologica, 99, 811-820.

Baldomero, H., Aljurf, M., Zaidi, S.Z.A., Hashmi, S.K., Ghavamzadeh, A., Elhaddad, A., Hamladji, R.M., Ahmed, P., Torjemane, L., Abboud, M., Tbakhi, A., Khabori, M.A., El Quessar, A., Bazuaye, N., Bekadja, M.A., Adil, S., Fahmy, O., Ramzi, M., Ibrahim, A., Alseraihy, A., Ben Abdejalil, N., Sarhan, M., Huneini, M.A., Mahmal, L., ElSolh, H., Hussain, F., Nassar, A., Al-Hashmi, H., Hamidieh, A.A., Pasquini, 
M., Kodera, Y., Kroger, N., Mohty, M., Jaimovich, G., Rolon, J.M., Paulson, K., Greinix, H., Weisdorf, D., Horowitz, M., Nunez, J., Gratwohl, A., Passweg, J., Koh, M., Szer, J., Niederwieser, D., Novitzky, N., East, M., African, B., Marrow Transplantation, G., the Worldwide Network for, B. \& Marrow, T. (2019) Narrowing the gap for hematopoietic stem cell transplantation in the EastMediterranean/African region: comparison with global HSCT indications and trends. Bone Marrow Transplant, 54, 402-417.

Bazuaye, N., Nwogoh, B., Ikponmwen, D., Irowa, O., Okugbo, S., Isa, I., Ighodaro, E., Aina, Y.I., Osaguona, A., Idemudia, O., Iyoha, O., Ighosewe, O., Osaghae, D. \& Bucher, C. (2014) First successful allogeneic hematopoietic stem cell transplantation for a sickle cell disease patient in a low resource country (Nigeria): a case report. Ann Transplant, 19, 210-213.

Bernaudin, F., Verlhac, S., Peffault de Latour, R., Dalle, J.H., Brousse, V., Petras, E., Thuret, I., Paillard, C., Neven, B., Galambrun, C., Divialle-Doumdo, L., Pondarre, C., Guitton, C., Missud, F., Runel, C., Jubert, C., Elana, G., DucrosMiralles, E., Drain, E., Taieb, O., Arnaud, C., Kamdem, A., Malric, A., ElmalehBerges, M., Vasile, M., Leveille, E., Socie, G., Chevret, S. \& Investigators, D.T. (2019) Association of Matched Sibling Donor Hematopoietic Stem Cell Transplantation With Transcranial Doppler Velocities in Children With Sickle Cell Anemia. JAMA, 321, 266-276.

Bhatia, M. \& Sheth, S. (2015) Hematopoietic stem cell transplantation in sickle cell disease: patient selection and special considerations. J Blood Med, 6, 229-238.

Bray, F., Ferlay, J., Soerjomataram, I., Siegel, R.L., Torre, L.A. \& Jemal, A. (2018) Global cancer statistics 2018: GLOBOCAN estimates of incidence and mortality worldwide for 36 cancers in 185 countries. CA Cancer J Clin, 68, 394-424.

Das, K., Khanna, T. \& Agrawal, N. (2018) Establishing Hematopoietic Stem Cell Transplant Unit in Resource Limited Setting: A Critical Analysis of Indian Council of Medical Research 2017 Guidelines. J Transplant, 2018, 1292307.

Drammeh, B., De, A., Bock, N., Pathak, S., Juma, A., Kutaga, R., Mahmoud, M., Haule, D., Sembucha, S., Chang, K., Nkya, E., Kuehnert, M. \& Marfin, A.A. (2018) Estimating Tanzania's National Met and Unmet Blood Demand From a Survey of a Representative Sample of Hospitals. Transfus Med Rev, 32, 36-42.

Eapen, M., Brazauskas, R., Walters, M.C., Bernaudin, F., Bo-Subait, K., Fitzhugh, C.D., Hankins, J.S., Kanter, J., Meerpohl, J.J., Bolanos-Meade, J., Panepinto, J.A., Rondelli, D., Shenoy, S., Williamson, J., Woolford, T.L., Gluckman, E., Wagner, J.E. \& Tisdale, J.F. (2019) Effect of donor type and conditioning regimen intensity on allogeneic transplantation outcomes in patients with sickle cell disease: a retrospective multicentre, cohort study. Lancet Haematol, 6, e585e596.

Faulkner, L.B. (2013) Setting up low-risk bone marrow transplantation for children with thalassemia may facilitate pediatric cancer care. South Asian J Cancer, 2, 109-112.

Faulkner, L.B., Uderzo, C. \& Masera, G. (2013) International cooperation for the cure and prevention of severe hemoglobinopathies. J Pediatr Hematol Oncol, 35, 419-423. 
Gluckman, E., Cappelli, B., Bernaudin, F., Labopin, M., Volt, F., Carreras, J., Pinto Simoes, B., Ferster, A., Dupont, S., de la Fuente, J., Dalle, J.H., Zecca, M., Walters, M.C., Krishnamurti, L., Bhatia, M., Leung, K., Yanik, G., Kurtzberg, J., Dhedin, N., Kuentz, M., Michel, G., Apperley, J., Lutz, P., Neven, B., Bertrand, Y., Vannier, J.P., Ayas, M., Cavazzana, M., Matthes-Martin, S., Rocha, V., Elayoubi, H., Kenzey, C., Bader, P., Locatelli, F., Ruggeri, A., Eapen, M., Eurocord, t.P.W.P.o.t.E.S.f.B., Marrow, T., the Center for International, B. \& Marrow Transplant, R. (2017) Sickle cell disease: an international survey of results of HLA-identical sibling hematopoietic stem cell transplantation. Blood, 129, 1548-1556.

Gomez-Almaguer, D. (2002) The simplification of the SCT procedures in developing countries has resulted in cost-lowering and availability to more patients. Int J Hematol, 76 Suppl 1, 380-382.

Gratwohl, A., Baldomero, H., Aljurf, M., Pasquini, M.C., Bouzas, L.F., Yoshimi, A., Szer, J., Lipton, J., Schwendener, A., Gratwohl, M., Frauendorfer, K., Niederwieser, D., Horowitz, M., Kodera, Y., Worldwide Network of, B. \& Marrow, T. (2010) Hematopoietic stem cell transplantation: a global perspective. JAMA, 303, 1617-1624.

Harif, M., Weisdorf, D., Novitzky, N., Szer, J., Mahmal, L., Benakli, M., Ben Othman, T., Bazuaye, N., McGrath, E., Eldridge, P.W., Torjemane, L., Madani, A., Ahmed Nacer, R., Belkhedim, R., Rasheed, W., Ahmed, S.O., Kodera, Y., Aljurf, M., Niederwieser, D.W. \& Quessar, A. (2019) Special report: Summary of the first meeting of African Blood and Marrow Transplantation (AfBMT) group, Casablanca, Morocco, April 19-21, 2018 held under the auspices of the Worldwide Network for Blood and Marrow Transplantation (WBMT). Hematol Oncol Stem Cell Ther.

Hashmi, S.K., Srivastava, A., Rasheed, W., Adil, S., Wu, T., Jagasia, M., Nassar, A., Hwang, W.Y.K., Hamidieh, A.A., Greinix, H.T., Pasquini, M.C., Apperley, J.F. \& Aljurf, M. (2017) Cost and quality issues in establishing hematopoietic cell transplant program in developing countries. Hematol Oncol Stem Cell Ther, 10, 167-172.

Kulkarni, U. \& George, B. (2019) Access to hematopoietic stem-cell transplantation in India. J Postgrad Med, 65, 1-4.

Leak, S.A., Mmbaga, L.G., Mkwizu, E.W., Mapendo, P.J. \& Henke, O. (2020) Hematological malignancies in East Africa-Which cancers to expect and how to provide services. PLoS One, 15, e0232848.

Makani, J., Lyimo, M., Magesa, P. \& Roberts, D.J. (2017) Strengthening medical education in haematology and blood transfusion: postgraduate programmes in Tanzania. Br J Haematol, 177, 838-845.

Niederwieser D, H.B., Yoshiko Atsuta, Mahmoud Aljurf, Adriana Seber, Hildegard T. Greinix, Mickey Koh, Nina Worel, Sebastian Galeano, Gregorio Jaimovich , Juliana Martinez Rolon, Yoshihisa Kodera, Malek Benakli, Nosa Bazuaye, Cristobal Augusto Frutos Ortiz, Rolandas Gerbutavicius , Alaa M. Elhaddad, Nicolas Novitzky, Jeffrey Szer, Jakob R. Passweg, Nicolaus Kröger , Daniel J. Weisdorf, Marcelo C. Pasquini (2019) One and Half Million Hematopoietic Stem Cell Transplants (HSCT). Dissemination, Trends and Potential to 
Improve Activity By Telemedicine from the Worldwide Network for Blood and Marrow Transplantation (WBMT). Blood, 134.

Pasquini, M.C., Srivastava, A., Ahmed, S.O., Aljurf, M., Atsuta, Y., Doleysh, C., Galeano, S., Gluckman, E., Greinix, H., Hale, G., Hari, P., Hashmi, S.K., Kamani, N., Laughlin, M.J., Niederwieser, D., Seber, A., Szer, J., Snowden, J.A., Van Biesen, K., Watry, P., Weisdorf, D.J. \& Apperley, J. (2019) Worldwide Network for Blood and Marrow Transplantation (WBMT) recommendations for establishing a hematopoietic cell transplantation program (Part I): Minimum requirements and beyond. Hematol Oncol Stem Cell Ther.

Piel, F.B., Patil, A.P., Howes, R.E., Nyangiri, O.A., Gething, P.W., Dewi, M., Temperley, W.H., Williams, T.N., Weatherall, D.J. \& Hay, S.I. (2013) Global epidemiology of sickle haemoglobin in neonates: a contemporary geostatistical model-based map and population estimates. Lancet, 381, 142-151.

Ruiz-Delgado, G.J. \& Ruiz-Arguelles, G.J. (2012) A Mexican way to cope with stem cell grafting. Hematology, 17 Suppl 1, S195-197.

Snowden, J.A., McGrath, E., Duarte, R.F., Saccardi, R., Orchard, K., Worel, N., Kuball, J., Chabannon, C. \& Mohty, M. (2017) JACIE accreditation for blood and marrow transplantation: past, present and future directions of an international model for healthcare quality improvement. Bone Marrow Transplant, 52, 13671371.

Yeh, A.C., Khan, M.A., Harlow, J., Biswas, A.R., Akter, M., Ferdous, J., Ara, T., Islam, M., Caron, M., Barron, A.M., Moran, J., Brezina, M., Nazneen, H., Kamruzzaman, M., Saha, A., Marshall, A., Afrose, S., Stowell, C., Preffer, F., Bangsberg, D., Goodman, A., Attar, E., McAfee, S., Spitzer, T.R. \& Dey, B.R. (2018) Hematopoietic Stem-Cell Transplantation in the Resource-Limited Setting: Establishing the First Bone Marrow Transplantation Unit in Bangladesh.J Glob Oncol, 4, 1-10. 